\title{
Impact of adolescent complex regional pain syndrome on the psychopathology of young men ahead of military service: a retrospective cohort analysis of Korean conscription data
}

\author{
Shin-Heon Lee, Myeong-Jin Ko, Taek-Kyun Nam, Jeong-Taik Kwon and Yong-Sook Park *i)
}

\begin{abstract}
Background: The relationship between physical and psychopathological features in complex regional pain syndrome (CRPS) has been a subject of constant interest, but no data are available in adolescents. Therefore, we aimed to identify the factors associated with psychopathology in adolescents with CRPS ahead of military service.

Methods: We retrospectively reviewed all conscription examinees who had completed a Military Personality Inventory (MPI) during a period between February 2013 and December 2016. A total of 63 persons with a history of CRPS (19-years of age for all) were enrolled. Basic demographic and pain-related data were analyzed to examine their association with MPI results. The mean FGR score as well as the 8 subdomain scores were compared between those with pain duration at $<15$ months $(n=30)$ versus $\geq 15$ months $(n=33)$. Binary MPI results (normal-abnormal) were also compared between the two groups.

Results: In multivariate analysis, abnormal MPI was associated with pain duration, with an odds ratio $(O R)$ at 1.05 for every 1-month increase (95\% confidence interval $(C l) 1.02-1.08 ; P=0.002$ ). Subjects with pain duration at $\geq 15$ months have lower faking good response score $(P<0.001$ vs. those with pain duration at $<15$ months), and higher abnormal MPI result rate, faking bad response, inconsistency, anxiety, depression, somatization, paranoid, personality disorder cluster $\mathrm{A}$, and personality disorder cluster B scores $(P<0.05)$. Pain duration was significantly associated with the MPI variables.
\end{abstract}

Conclusions: Pain duration is associated with psychopathology in adolescents with CRPS. Psychopathologic features increased as the disease duration increased. A comprehensive understanding of time-dependent psychopathological factors could support the planning of multimodal approaches for managing adolescent CRPS.

Keywords: Chronic pain, Complex regional pain syndromes, Psychopathology, Personality inventory, Adolescent, Military personnel

\footnotetext{
* Correspondence: cuttage@cau.ac.kr

Department of Neurosurgery, College of Medicine, Chung-Ang University,

Seoul 06973, South Korea
}

(c) The Author(s). 2020 Open Access This article is licensed under a Creative Commons Attribution 4.0 International License, which permits use, sharing, adaptation, distribution and reproduction in any medium or format, as long as you give appropriate credit to the original author(s) and the source, provide a link to the Creative Commons licence, and indicate if changes were made. The images or other third party material in this article are included in the article's Creative Commons licence, unless indicated otherwise in a credit line to the material. If material is not included in the article's Creative Commons licence and your intended use is not permitted by statutory regulation or exceeds the permitted use, you will need to obtain permission directly from the copyright holder. To view a copy of this licence, visit http://creativecommons.org/licenses/by/4.0/ The Creative Commons Public Domain Dedication waiver (http://creativecommons.org/publicdomain/zero/1.0/) applies to the data made available in this article, unless otherwise stated in a credit line to the data. 


\section{Background}

Complex regional pain syndrome (CRPS) is a severe pain disorder that affects one or more extremities and typically develops after a trauma or nerve lesions. It is clinically characterized by sensory, autonomic, motor, and trophic symptoms. Causes of CRPS include autoimmune response, abnormal cytokine production, inflammatory processes, sympathetic-sensory disorders, and functional changes in the central nervous system [1].

The perspective that psychological factors contribute to the development of the disease has been the topic of constant controversy [2-4]. Nonetheless, researchers and clinicians agree on the reciprocal relationship between the physical and psychological components of pain [5]. Although it has been continuously debated whether these symptoms are the result or the cause of this debilitating disease, it is clear that CRPS is associated with psychological sequelae, such as depression, anxiety, poor quality of life, and functional disabilities [5, 6]. Despite these profound associations, previous studies have only focused on the presence of CRPS and psychopathology but have not separately investigated the painrelated factors and the demographic (and other) factors that potentially affect psychopathology.

CRPS could occur in both adults and adolescents [7]. Adolescent CRPS typically starts at $12-13$ years, with a mean time from initial signs to diagnosis at 12 months $[7,8]$. Compared with adult CRPS, adolescent CRPS has a relatively mild course and responds well to treatment [9]. Despite the relatively benign disease course, the risk of CRPS-induced psychopathology is a major challenge. Elevated risks of somatization, anxiety, and depression have been identified among patients with adolescent or pediatric CRPS [10]. Additionally, pain duration has been associated with suicidal ideation, and this association is mediated by depression among patients with "amplified pain", the spectrum of which includes CRPS [11]. Considering the developmental and social aspects relevant to adolescent mental health, the psychopathology associated with adolescent CRPS is an important problem worthy of investigation and intervention.

In this study, we attempted to identify the factors that are associated with psychopathology among adolescents with CRPS ahead of military service.

\section{Methods}

\section{Patients}

This is a registry-based retrospective cohort study. All conscription examinees during a period between February 2013 and December 2016 were screened. Among the 1,418,519 19-year-old examinees evaluated for Korean conscription from February 2013 through December 2016, 72 self-reported medical histories of CRPS. We excluded seven conscripts who had a medical history of other psychiatric disorders before the diagnosis of CRPS and two conscripts whose pain symptoms did not correspond with the International Association for the Study of Pain (IASP) Budapest Criteria for CRPS according to the findings of physical examination. The final analysis included 63 subjects. The study received ethical approval from the Korean Military Manpower Administration. Anonymity was maintained throughout the study. Informed consent was not applicable.

\section{Demographic \& disease characteristics}

CRPS symptoms and signs were primarily documented as per medical records and verified by doctors during the overall pre-conscription physical assessments. CRPS type, site, symptom, intensity, and duration of the pain, as well as the treatment (physical or pharmacological therapy, sympathetic nerve intervention, or spinal cord stimulation), were recorded. Demographic characteristics in the analysis included age, sex, education, socioeconomic status, and parental coresidence status.

The IASP Budapest Criteria [12] were used to assess self-reported symptoms as well as signs observed during physical examinations. Harden et al. [13] developed the CRPS Severity Score (CSS), which evaluates the severity of CRPS on a 17-point scale (symptoms, 8 points; signs, 9 points). This scoring system corresponds well with the ISAP Budapest Criteria but provides assessment with a continuous scale $[13,14]$. In this study, a modified CRPS severity score (mCSS) system that consisted of signs only (maximum score: 9 points) was used. The pain was assessed using an 11-point numerical rating scale (NRS; lowest score: 0; highest score: 10) [15].

\section{Psychopathologic assessment}

The Military Personality Inventory (MPI) [16] was used to evaluate personality structure and psychopathology [16]. The MPI is a multiphasic personality inventory developed by the Korea Institute for Defense Analysis (KIDA) in 2006 and is based on the Minnesota Multiphasic Personality Inventory (MMPI) $[17,18]$. It consists of 238 questions divided into four sections. The results are expressed as standardized T-scores [17, 18]. The overall MPI result was classified as "normal" when the results of the combined MPI scales met the conscription criteria, and MPI results were classified as "abnormal" when this condition was not satisfied $[17,18]$.

The validity and reliability of the MPI have been established by previous research [19-21]. In a feasibility study, MPI scores differed significantly between the maladjusted and psychotic group and the healthy controls [22]. The test-retest reliability was 0.69 (95\% confidence interval [CI], 0.63-0.75), and Cronbach's alpha was 0.72 (95\% CI, 0.67-0.76) [23]. 
Details of MPI have been described previously [24]. Briefly, MPI is based on the results of the four sections (validity, neurosis, psychosis, and personality disorders). The validity section consists of four scales: faking good response (FGR), faking bad response (FBR), infrequency (INF), and inconsistency (INC). The neurosis section consists of anxiety (ANX), depression (DEP), and somatization (SOM) scales. For each of these scales, a higher score indicates a greater tendency to manifest mental illness symptoms. The psychosis section consists of schizophrenia (SCZ) and paranoid (PAR) scales. The personality disorder section consists of personality disorder cluster A (PDA), which comprises paranoid personality disorder, schizoid personality disorder, and schizotypal personality disorder, and personality disorder cluster B (PDB), which comprises antisocial personality disorder, borderline personality disorder, histrionic personality disorder, and narcissistic personality disorder [24].

We examined both the scores using the abovementioned scales and the overall rate of "normal" versus "abnormal". Subjects with pain duration at $<15$ months $(n=30)$ versus $\geq 15$ months $(n=33)$ were compared.

\section{Statistical analysis}

SPSS Statistics for Windows, version 22 (IBM Corp., Armonk, New York, USA) and MedCalc, version 19.0.7 (MedCalc Software, Mariakerke, Belgium) were used for all statistical analyses. Categorical variables are expressed as frequencies or percentages and analyzed using the chi-square test or Fisher's exact test. The factors associated with abnormal MPI results were analyzed using multivariate logistic regression. Receiver operating characteristic (ROC) curve analysis was performed to estimate the predictive accuracy of pain duration for the binary (normal-abnormal) MPI results. The cutoff values were selected to maximize the sum of sensitivity and specificity. Continuous variables with normal distribution were analyzed using Student's $t$-test. Continuous variables not following normal distribution were analyzed using the Mann-Whitney $U$ test. To analyze the impact of each clinical measurement on the MPI scores, linear regression analysis was performed. Multivariable linear regression analysis was performed to analyze the combined effect of the clinical measurements on MPI scores. $P$ values $<0.05$ were considered statistically significant. For multiple comparisons, the Bonferroni correction was conducted.

\section{Results}

\section{Patient characteristics}

Sixty-three male subjects with CRPS had a median age of 19.3 years and mean pain duration of $27.41 \pm 2.67$ months. Of the 63 adolescents with CRPS, 20 (31.7\%)
Table 1 Basic demographics and pain characteristics of adolescents with complex regional pain syndrome (CRPS)

\begin{tabular}{|c|c|}
\hline Characteristic & Value \\
\hline Age [year, median (range)] & $19.3(19-20)$ \\
\hline Male $[n(\%)]$ & $63(100)$ \\
\hline \multicolumn{2}{|l|}{ Education $[n(\%)]$} \\
\hline College or more & $40(63.5)$ \\
\hline High school or less & $23(36.5)$ \\
\hline \multicolumn{2}{|l|}{ Socioeconomic status [n (\%)] } \\
\hline High & $8(12.7)$ \\
\hline Middle & $33(52.4)$ \\
\hline Low & $22(34.9)$ \\
\hline \multicolumn{2}{|l|}{ Parental coresidence status [n (\%)] } \\
\hline Both & $54(85.7)$ \\
\hline One parent & $8(12.7)$ \\
\hline None & $1(1.6)$ \\
\hline Abnormal MPI results [n (\%)] & $20(31.7)$ \\
\hline $\operatorname{mCSS}(2-9, x \pm s)$ & $4.05 \pm 1.58$ \\
\hline NRS $(0-10, x \pm s)$ & $6.25 \pm 1.57$ \\
\hline Pain duration (month, $x \pm s$ ) & $27.41 \pm 2.67$ \\
\hline \multicolumn{2}{|l|}{ CRPS type $[n(\%)]$} \\
\hline 1 & $49(77.8)$ \\
\hline$\|$ & $14(22.2)$ \\
\hline \multicolumn{2}{|l|}{ Affected site $[n(\%)]$} \\
\hline Upper extremity & $18(28.6)$ \\
\hline Lower extremity & $43(68.3)$ \\
\hline Multiple & $2(3.2)$ \\
\hline \multicolumn{2}{|l|}{ Symptomatic presentation [n (\%)] } \\
\hline Allodynia & $45(71.4)$ \\
\hline Hyperalgesia & $42(66.7)$ \\
\hline Temperature asymmetry & $34(54.0)$ \\
\hline Skin color asymmetry & $36(57.1)$ \\
\hline Sweating asymmetry & $28(44.4)$ \\
\hline Asymmetric edema & $26(41.3)$ \\
\hline Trophic changes & $12(19.0)$ \\
\hline Motor dysfunction & $21(33.3)$ \\
\hline Decreased active range of motion & $8(12.7)$ \\
\hline \multicolumn{2}{|l|}{ Treatment $[n(\%)]$} \\
\hline Physical or pharmacological therapy & $21(33.3)$ \\
\hline Sympathetic nerve intervention & $33(52.4)$ \\
\hline Spinal cord stimulation & $9(14.3)$ \\
\hline
\end{tabular}

MPI Military Personality Inventory, mCSS Modified Complex regional pain syndrome Severity Score, NRS Numerical rating scale, CRPS Complex regional pain syndrome

had abnormal MPI results. Forty-nine subjects were diagnosed as type I CRPS (77.8\%) and 14 were diagnosed as type II CRPS. Demographic and pain characteristics 
including education, socioeconomic status, parental coresidence status, mCSS, NRS score, affected site, symptomatic presentation, and treatment modality, are shown in Table 1.

\section{Factors associated with abnormal MPI results}

In the multivariate logistic regression analysis, abnormal MPI results were associated with pain duration, with an odds ratio $(O R)$ at 1.05 with every 1 -month increase (95\% CI, 1.02-1.08; $P=0.002$, Table 2). No other factors were associated with abnormal MPI.

\section{Prediction of MPI outcomes with pain duration}

At a cutoff value at 15 months, pain duration predicted abnormal MPI with the area under the curve (AUC) in the ROC analysis at $0.784(95 \% \mathrm{CI}, 0.663-0.878 ; P<$
$0.001)$. The sensitivity and specificity were 85.0 and $65.1 \%$, respectively (Fig. 1 ).

\section{Comparison of those with pain duration at $<15$ vs. $\geq 15$ months}

There were no significant differences between subjects with pain duration at $<15$ vs. $\geq 15$ months in age, education, socioeconomic status, parental coresidence status, mean mCSS, mean NRS score, CRPS type, affected site, and treatment modality (Table 3). The abnormal MPI result rate was significantly higher in subjects with pain duration at $\geq 15$ months than those with pain duration at $<15$ months $(10.0 \%$ vs. $51.5 \%, P<0.001)$. The mean FGR score was significantly lower in subjects with pain duration at $\geq 15$ months $(55.3 \pm 2.5$ vs. $42.0 \pm 2.7, P<0.001)$. Subjects with pain duration at $\geq 15$ months also had higher FBR $(52.1 \pm 1.7$ vs. $59.8 \pm 2.4 ; \quad P<0.05)$, INC

Table 2 Influence of demographics and pain characteristics on Military Personality Inventory (MPI) results of adolescents with complex regional pain syndrome (CRPS)

\begin{tabular}{|c|c|c|c|c|c|}
\hline \multirow[t]{2}{*}{ Variable } & \multicolumn{2}{|l|}{ Prevalence } & \multicolumn{3}{|c|}{ Logistic regression analysis } \\
\hline & Normal MPI $(n=43)$ & Abnormal MPI $(n=20)$ & $\overline{O R}$ & $95 \% \mathrm{Cl}$ & $P$ \\
\hline Age (year, median) & 19.35 & 19.28 & 0.25 & $0.01-4.24$ & 0.334 \\
\hline \multicolumn{6}{|l|}{ Education $[n(\%)]$} \\
\hline College or more & $28(65.1)$ & $12(60.0)$ & 1 & & \\
\hline High school or less & $15(34.9)$ & $8(40.0)$ & 0.99 & $0.22-4.52$ & 0.986 \\
\hline \multicolumn{6}{|l|}{ Socioeconomic status [n (\%)] } \\
\hline High & $7(16.3)$ & $1(5.0)$ & 1 & & \\
\hline Middle & $23(53.5)$ & $10(50.0)$ & 14.38 & $0.50-413.72$ & 0.120 \\
\hline Low & $13(30.2)$ & $9(45.0)$ & 23.71 & $0.81-695.42$ & 0.066 \\
\hline \multicolumn{6}{|l|}{ Parental coresidence status [n (\%)] } \\
\hline Both & $36(83.7)$ & $18(90.0)$ & 1 & & \\
\hline One parent & $6(14.0)$ & $2(10.0)$ & 0.41 & $0.02-7.00$ & 0.536 \\
\hline None & $1(2.3)$ & $0(0.0)$ & 0 & 0 & 1.000 \\
\hline mCSS (2-9) & 4.21 & 3.70 & 0.73 & $0.37-1.43$ & 0.358 \\
\hline NRS $(0-10)$ & 6.40 & 5.95 & 0.97 & $0.56-1.68$ & 0.358 \\
\hline Pain duration (month) & 21.40 & 40.35 & 1.05 & $1.02-1.08$ & $0.002^{*}$ \\
\hline \multicolumn{6}{|l|}{ CRPS type $[n(\%)]$} \\
\hline । & $34(79.1)$ & $15(75.0)$ & 1 & & \\
\hline$\|$ & $9(20.9)$ & $5(25.0)$ & 3.76 & $0.61-23.33$ & 0.155 \\
\hline \multicolumn{6}{|l|}{ Affected site $[n(\%)]$} \\
\hline Upper extremity & $12(27.9)$ & $6(30.0)$ & 1 & & \\
\hline Lower extremity & $29(67.4)$ & $14(70.0)$ & 0.98 & $0.20-4.90$ & 0.983 \\
\hline Multiple & $2(4.7)$ & $0(0.0)$ & 0 & 0 & 0.999 \\
\hline \multicolumn{6}{|l|}{ Treatment $[n(\%)]$} \\
\hline Physical or pharmacological therapy & $15(34.9)$ & $6(30.0)$ & 1 & & \\
\hline Sympathetic nerve intervention & $22(51.2)$ & $11(55.0)$ & 6.90 & $0.76-62.51$ & 0.086 \\
\hline Spinal cord stimulation & $6(14.0)$ & $3(15.0)$ & 4.06 & $0.38-43.02$ & 0.245 \\
\hline
\end{tabular}



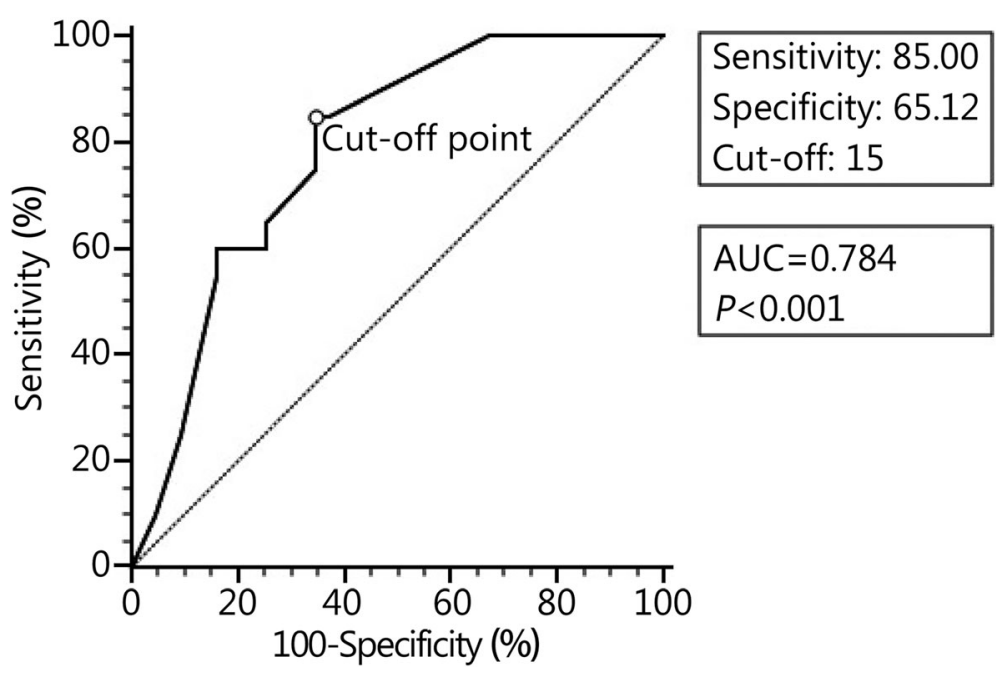

$\mathrm{AUC}=0.784$

$P<0.001$

Fig. 1 Receiver operating characteristic (ROC) curves using pain duration as a predictor and Military Personality Inventory (MPI) results (normal vs. abnormal) as a binary outcome

(50.6 \pm 1.9 vs. $61.8 \pm 2.3, P<0.001)$, ANX $(51.4 \pm 2.0$ vs. $64.7 \pm 2.5, P<0.001)$, DEP $(48.9 \pm 1.6$ vs. $63.1 \pm 2.3, P<$ $0.001)$, $\mathrm{SOM}(52.5 \pm 2.5$ vs. $66.3 \pm 2.5, P<0.001)$, PAR $(51.1 \pm 1.5$ vs. $58.8 \pm 2.0, P<0.05)$, PDA $(50.9 \pm 1.6$ vs. $63.7 \pm 2.3, P<0.001)$, and PDB $(49.2 \pm 1.6$ vs. $61.6 \pm 2.4$, $P<0.001$ ) scores (Table 4).

\section{Impact of pain severity and pain duration on the MPI scales}

Univariate linear regression analysis indicated that $\mathrm{mCSS}$ is associated with SOM and PDA scores $(P<0.05)$. Pain duration was associated with FGR, INC, ANX, DEP, SOM, SCZ, PAR, PDA, and PDB scores $(P<0.05)$. In multivariate linear regression, pain duration was associated with FGR, INC, ANX, DEP, SOM, PAR, PDA, and PDB scores $(P<0.05$ for all, Table 5$)$.

\section{Discussion}

A chronic state of illness or pain is often associated with reactive depression and anxiety as well as higher scores on many of the MMPI subscales [25, 26]. Additionally, among adolescents and children with CRPS, the risks of somatization, anxiety, and depression are high, and the duration of pain and depression has been shown to be associated with suicidal ideation $[10,11]$. The results of the present study were consistent with previous studies in which the frequencies of anxiety, depression, and personality disorders were high among patients with chronic CRPS [27, 28].

We speculated that demographic characteristics, pain intensity, pain duration, clinical manifestations, and treatment modality invasiveness are associated with the psychopathology of adolescent CRPS. However, we failed to find associations between the psychopathology of adolescents with CRPS with demographic characteristics, the number of items in the IASP criteria, pain intensity, type of CRPS, the site of morbidity, or treatment modalities. Pain duration was the only factor that was significantly associated with psychopathology in our study.

Previous studies indicated that pain intensity is associated with psychopathology among patients with chronic pain $[29,30]$. Such associations have also been observed among adult CRPS patients [31, 32]. We speculated that pain intensity would be associated with psychopathology in adolescent CRPS, but did not find evidence to support such an association. According to previous research by Logan et al. [33], children and adolescents from 7 to 18 years of age with CRPS had higher pain intensity ratings than other chronic pain groups. However, anxiety and depression were within the normal range in the CRPS group and did not differ from other chronic pain groups [33]. The pain duration among CRPS patients included in their study was $13.00 \pm 2.9$ months [33]. The fact that anxiety and depression did not differ from normative comparison data may be attributed to the relatively short pain duration.

Mesaroli et al. [34] retrospectively reviewed the charts of 59 CRPS patients with a mean age of $13.2 \pm 2.6$ years. The mean symptom duration was $35.7 \pm 43.8$ weeks. Their investigation using self-report questionnaires showed that anxiety, depression, and somatization were within normal ranges relative to age- and sex-matched peers [34]. However, through clinical diagnostic interviews, $39 \%$ of patients were diagnosed as having anxiety disorders, $12 \%$ had depressive disorders, 13\% had somatic symptom disorders, and $37 \%$ had some type of past adverse events. There was a difference between the selfreporting and clinical interview methods. 
Table 3 Comparison of demographics and pain characteristics between the two complex regional pain syndrome (CRPS) groups according to pain duration

\begin{tabular}{|c|c|c|c|}
\hline Variable & Pain duration $<15$ mon group $(n=30)$ & Pain duration $\geq 15$ mon group $(n=33)$ & $P$ \\
\hline Age [year, median (range)] & $19.3(19.0-20.0)$ & $19.3(19.0-20.0)$ & 0.086 \\
\hline Male $[n(\%)]$ & $30(100.0)$ & $33(100.0)$ & \\
\hline \multicolumn{4}{|l|}{ Education [n (\%)] } \\
\hline College or more & $20(66.7)$ & $20(60.6)$ & \multirow[t]{2}{*}{0.617} \\
\hline High school or less & $10(33.3)$ & $13(39.4)$ & \\
\hline \multicolumn{4}{|l|}{ Socioeconomic status [n (\%)] } \\
\hline High & $5(16.7)$ & $3(9.1)$ & \multirow[t]{3}{*}{0.385} \\
\hline Middle & $17(56.7)$ & $16(48.5)$ & \\
\hline Low & $8(26.7)$ & $14(42.4)$ & \\
\hline \multicolumn{4}{|l|}{ Parental coresidence status [n (\%)] } \\
\hline Both & $27(90.0)$ & $27(81.8)$ & \multirow[t]{3}{*}{0.710} \\
\hline One parent & $3(10.0)$ & $5(15.2)$ & \\
\hline None & $0(0.0)$ & $1(3.0)$ & \\
\hline mCSS (2-9) & $4.53 \pm 1.72$ & $3.61 \pm 1.32$ & 0.019 \\
\hline NRS $(0-10)$ & $6.40 \pm 1.65$ & $6.12 \pm 1.49$ & 0.485 \\
\hline \multicolumn{4}{|l|}{ CRPS type $[n(\%)]$} \\
\hline । & $23(76.7)$ & $26(78.8)$ & \multirow[t]{2}{*}{0.841} \\
\hline$\|$ & $7(23.3)$ & $7(21.2)$ & \\
\hline \multicolumn{4}{|l|}{ Affected site [n (\%)] } \\
\hline Upper extremity & $10(33.3)$ & $8(24.2)$ & \multirow[t]{3}{*}{0.209} \\
\hline Lower extremity & $18(60.0)$ & $25(75.8)$ & \\
\hline Multiple & $2(6.7)$ & $0(0.0)$ & \\
\hline \multicolumn{4}{|l|}{ Symptomatic presentation [n (\%)] } \\
\hline Allodynia & $22(73.3)$ & $24(72.7)$ & 1 \\
\hline Hyperalgesia & $22(73.3)$ & $21(63.6)$ & 0.410 \\
\hline Temperature asymmetry & $17(56.7)$ & $17(51.5)$ & 0.680 \\
\hline Skin color asymmetry & $21(70.0)$ & $16(48.5)$ & 0.083 \\
\hline Sweating asymmetry & $17(56.7)$ & $11(33.3)$ & 0.062 \\
\hline Asymmetric edema & $14(46.7)$ & $12(36.4)$ & 0.406 \\
\hline Trophic changes & $8(26.7)$ & $4(12.1)$ & 0.142 \\
\hline Motor dysfunction & $9(30.0)$ & $12(36.4)$ & 0.590 \\
\hline Decreased active range of motion & $6(20.0)$ & $2(6.1)$ & 0.136 \\
\hline \multicolumn{4}{|l|}{ Treatment $[n(\%)]$} \\
\hline Physical or pharmacological therapy & $8(26.7)$ & $13(39.4)$ & \multirow[t]{3}{*}{0.540} \\
\hline Sympathetic nerve intervention & $18(60.0)$ & $15(45.5)$ & \\
\hline Spinal cord stimulation & $4(13.3)$ & $5(15.2)$ & \\
\hline
\end{tabular}

mCSS Modified Complex regional pain syndrome Severity Score, NRS Numerical rating scale, CRPS Complex regional pain syndrome

The onset age of CRPS symptoms among our subjects ranged from 13 to 19 years, and the mean pain duration was $27.41 \pm 2.67$ months. The age and pain duration of the participants in the current study differed from that in previous studies by Logan et al. [33] and Mesaroli et al. [34], but the key results are generally consistent.
As our study and both of these studies had retrospective designs, well-designed prospective studies are warranted.

Adolescent and pediatric CRPS have been associated with unique gender ratios $[7,8,34]$. CRPS is approximately 3 to 6 times more common among girls than boys $[7,8,34]$. The study sample investigated by 
Table 4 Comparison of Military Personality Inventory (MPI) results between the two complex regional pain syndrome (CRPS) groups according to pain duration

\begin{tabular}{llll}
\hline Variable & Pain duration $<\mathbf{1 5}$ mon group $(\boldsymbol{n}=\mathbf{3 0})$ & Pain duration $\geq \mathbf{1 5}$ mon group $(\boldsymbol{n}=\mathbf{3 3})$ & $\boldsymbol{P}$ \\
\hline Abnormal MPI results $[n(\%)]$ & $3(10)$ & $17(51.5)$ & $<0.001^{* *}$ \\
Faking good response $(x \pm s)$ & $55.3 \pm 2.5$ & $42.0 \pm 2.7$ & $<0.001^{* *}$ \\
Faking bad response $(x \pm s)$ & $52.1 \pm 1.7$ & $59.8 \pm 2.4$ & $0.012^{*}$ \\
Infrequency $(x \pm s)$ & $54.5 \pm 1.9$ & $60.6 \pm 3.0$ & 0.097 \\
Inconsistency $(x \pm s)$ & $50.6 \pm 1.9$ & $61.8 \pm 2.3$ & $<0.001^{* *}$ \\
Anxiety $(x \pm s)$ & $51.4 \pm 2.0$ & $64.7 \pm 2.5$ & $<0.001^{* *}$ \\
Depression $(x \pm s)$ & $48.9 \pm 1.6$ & $63.1 \pm 2.3$ & $<0.001^{* *}$ \\
Somatization $(x \pm s)$ & $52.5 \pm 2.5$ & $66.3 \pm 2.5$ & $<0.001^{* *}$ \\
Schizophrenia $(x \pm s)$ & $55.5 \pm 1.8$ & $61.1 \pm 2.9$ & 0.105 \\
Paranoid $(x \pm s)$ & $51.1 \pm 1.5$ & $58.8 \pm 2.0$ & $0.003^{*}$ \\
Personality disorder cluster A $(x \pm s)$ & $50.9 \pm 1.6$ & $63.7 \pm 2.3$ & $<0.001^{* *}$ \\
Personality disorder cluster B $(x \pm s)$ & $49.2 \pm 1.6$ & $61.6 \pm 2.4$ & $<0.001^{* *}$ \\
\hline
\end{tabular}

MPI Military personality inventory. ${ }^{*} P<0.05 .{ }^{*} P<0.001$

Mesaroli et al. [34] was also predominantly composed of females (74.6\%), and as previously mentioned, psychopathologic features were detected via clinical diagnostic interviews. Conversely, our study only included male subjects. Nonetheless, it is worth noting that the two previous studies had similar findings and that these results suggest that adolescent CRPS can manifest with psychopathology regardless of gender.

The stress process occurs as a bidirectional communication between the brain and the autonomic nervous system, the cardiovascular system, and the immune system through the neurological and endocrinological mechanisms responsible for cognition, perception, and behavior [35]. In "stressful" conditions, such as the experience of chronic pain, stress-related structural and functional plasticity can occur in corticolimbic structures, such as the hippocampus, amygdala, and the prefrontal cortex [35].

Recent studies have frequently reported that central neuroplasticity also progresses in CRPS [36-38]. Central neuroplasticity may occur as a form of change in gray matter or alterations in functional and white matter connectivity between brain regions [39]. These processes occur through mechanisms such as the unmasking or strengthening of silent or ineffective synapses, collateral sprouting, and the loss of gamma-aminobutyric acid (GABA) inhibition [39]. Several studies have suggested that gray matter volume is reduced in the insular cortex, nucleus accumbens, and prefrontal cortex of CRPS patients $[36,40]$. Additionally, gray matter volume decreases with disease prolongation and progression, corresponding with structural and functional changes in the brain over time in CRPS [41].

Interestingly, previous studies have shown a reverse change, with increased gray matter volume and enhanced functional and structural connectivity after early treatment in pediatric and adolescent CRPS [42, 43]. However, a study by Linnman et al. [44] revealed that pain-induced alterations of functional connectivity in the brain could persistent even in a recovered state after functional recovery. Maladaptation of this plasticity can lead to the continuation and worsening of pain and is associated with psychopathology [35, 45].

Early diagnosis and treatment are known to be the major factors associated with successful outcomes for adolescent CRPS patients [46]. Active suspicion of adolescent CRPS and appropriate therapeutic interventions should be enacted promptly after diagnosis due to the potentially harmful effects of CRPS on adolescent development and future health. This will improve the quality of life by reducing pain and by reducing psychopathology by potentially shortening the pain duration. Therefore, there is a need to approach adolescent CRPS with a more time-limited concept when planning the treatment of patients in clinical practice.

Korea has a military draft policy. In young soldiers, delays in the diagnosis and treatment of trauma-associated pain that may occur in the military are likely to lead to CRPS. The newly developed psychopathology of soldiers can cause various problems, such as self-harm and harm to fellow soldiers. Therefore, the possibility of psychopathology is especially important for soldiers with chronic pain. However, psychological screening and treatment in the military remain insufficient compared with clinical practice outside the military. Within the military as well, the diagnosis and treatment of CRPS would have to be carried out thoroughly in a more timelimited concept. Psychological evaluations should be conducted to soldiers at appropriate intervals considering psychopathology that can change over time and 
Table 5 Univariable and multivariate linear regression analysis of pain severity and duration on the Military Personality Inventory (MPI) scales

\begin{tabular}{|c|c|c|c|c|c|}
\hline \multirow[t]{2}{*}{ Variable } & \multirow[t]{2}{*}{ Predictor } & \multicolumn{2}{|c|}{ Univariate } & \multicolumn{2}{|c|}{ Multivariate } \\
\hline & & Std. $\beta$ & $P$ & Std. $\beta$ & $P$ \\
\hline \multirow[t]{3}{*}{ Faking good response } & mCSS & 0.192 & 0.132 & 0.077 & 0.560 \\
\hline & NRS & 0.134 & 0.294 & 0.093 & 0.466 \\
\hline & Pain duration & -0.347 & $0.005^{*}$ & -0.321 & $0.013+$ \\
\hline \multirow[t]{3}{*}{ Faking bad response } & mCSS & 0.003 & 0.982 & 0.055 & 0.693 \\
\hline & NRS & 0.011 & 0.934 & 0.007 & 0.961 \\
\hline & Pain duration & 0.180 & 0.157 & 0.196 & 0.146 \\
\hline \multirow[t]{3}{*}{ Infrequency } & mCSS & 0.003 & 0.979 & 0.050 & 0.716 \\
\hline & NRS & 0.092 & 0.472 & 0.094 & 0.476 \\
\hline & Pain duration & 0.247 & 0.051 & 0.266 & 0.046 \\
\hline \multirow[t]{3}{*}{ Inconsistency } & mCSS & -0.137 & 0.285 & -0.064 & 0.633 \\
\hline & NRS & 0.012 & 0.924 & 0.050 & 0.699 \\
\hline & Pain duration & 0.331 & $0.008^{*}$ & 0.317 & $0.016+$ \\
\hline \multirow[t]{3}{*}{ Anxiety } & mCSS & -0.209 & 0.100 & -0.086 & 0.495 \\
\hline & NRS & -0.068 & 0.596 & -0.017 & 0.885 \\
\hline & Pain duration & 0.454 & $<0.001^{* *}$ & 0.429 & $<0.001+$ \\
\hline \multirow[t]{3}{*}{ Depression } & $\mathrm{mCSS}$ & -0.240 & 0.058 & -0.111 & 0.360 \\
\hline & NRS & -0.051 & 0.689 & 0.009 & 0.935 \\
\hline & Pain duration & 0.506 & $<0.001^{* *}$ & 0.476 & $<0.001+$ \\
\hline \multirow[t]{3}{*}{ Somatization } & mCSS & -0.254 & $0.045^{*}$ & -0.156 & 0.224 \\
\hline & NRS & -0.050 & 0.696 & 0.017 & 0.888 \\
\hline & Pain duration & 0.415 & $<0.001^{* *}$ & 0.373 & $0.003+$ \\
\hline \multirow[t]{3}{*}{ Schizophrenia } & mCSS & 0.066 & 0.605 & 0.138 & 0.312 \\
\hline & NRS & 0.050 & 0.698 & 0.027 & 0.834 \\
\hline & Pain duration & 0.249 & $0.049^{*}$ & 0.289 & 0.030 \\
\hline \multirow[t]{3}{*}{ Paranoid } & mCSS & -0.193 & 0.130 & -0.062 & 0.625 \\
\hline & NRS & -0.104 & 0.419 & -0.061 & 0.619 \\
\hline & Pain duration & 0.431 & $<0.001^{* *}$ & 0.410 & $0.001+$ \\
\hline \multirow[t]{3}{*}{ Personality disorder cluster A } & mCSS & -0.263 & $0.037^{*}$ & -0.111 & 0.355 \\
\hline & NRS & -0.131 & 0.305 & -0.070 & 0.543 \\
\hline & Pain duration & 0.513 & $<0.001^{* *}$ & 0.478 & $<0.001+$ \\
\hline \multirow[t]{3}{*}{ Personality disorder cluster B } & mCSS & -0.146 & 0.254 & -0.035 & 0.784 \\
\hline & NRS & -0.013 & 0.917 & 0.022 & 0.856 \\
\hline & Pain duration & 0.434 & $<0.001^{* *}$ & 0.426 & $<0.001+$ \\
\hline
\end{tabular}

Std. $\beta$ Standardized beta, $m$ CSS Modified Complex regional pain syndrome Severity Score, NRS Numerical rating scale. ${ }^{*} P<0.05$. ${ }^{*} P<0.001 .+P<0.016$, adjusted significance level after Bonferroni corrections

treatment has to be followed even after the termination of pain. A multidisciplinary approach comprising psychological treatment should be initiated promptly when symptoms persist or worsen. Additionally, special attention should be paid when the soldier's pain lasts longer than 15 months according to our result. In particular, it is worthwhile to consider early discharge as necessary after re-evaluation of psychopathology during the service period in the case of mandatory military service.
This study has several limitations. First, the present study was a retrospective cohort analysis based on selfreported assessments. Considering the difference between self-reported assessments and clinical presentations [34], the use of self-reported assessments in our study could have introduced some bias, although the reliability and validity of the MPI have been evaluated extensively [22, 23]. Second, because all of the participants were approximately the same age ( 19 years old) and were 
all males, caution should be exercised when generalizing the results to the general public, and the possibility of an association between a young age of onset and a distinctive psychopathological pattern cannot be overlooked. The third limitation is the use of an unvalidated modified version of the CSS. Last, psychopathology can be affected by the pain but also it can affect the pain experience vice versa $[4,6]$. However, due to the nature of our data, we could not separately reveal the effect of the psychological characteristics on the experience of pain.

\section{Conclusions}

Pain duration is the main factor affecting psychopathology among adolescents with CRPS. Psychopathologic features increased as the disease duration increased. A comprehensive understanding of time-dependent psychopathological manifestations could support a multimodal approach for detecting and managing adolescent CRPS.

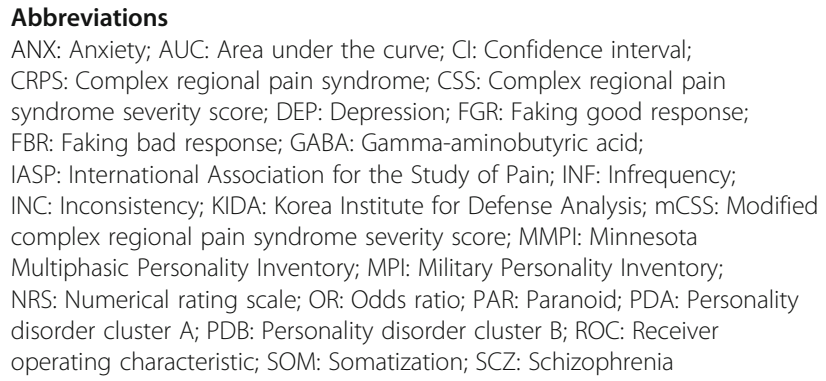

\section{Acknowledgments}

Not applicable.

\section{Authors' contributions}

SHL and YSP designed the study. SHL performed data collection and data analysis and drafted the manuscript. MJK, TKN, and JTK contributed to reviewing and editing the manuscript. YSP was in charge of overall direction and planning. All authors read and approved the final manuscript.

\section{Funding}

No funding was received for this research.

\section{Availability of data and materials}

The datasets used and analyzed during the current study are available from the corresponding author on reasonable request.

\section{Ethics approval and consent to participate}

This study was approved by the Korean Military Manpower Administration, and patients' details were anonymized in a secure database. As this study was a registry-based retrospective cohort study, informed consent was not obtained.

\section{Consent for publication}

Not applicable.

\section{Competing interests}

The authors declare that they have no competing interests.
Received: 3 December 2019 Accepted: 9 December 2020

Published online: 21 December 2020

\section{References}

1. Borchers A, Gershwin ME. Complex regional pain syndrome: a comprehensive and critical review. Autoimmun Rev. 2014;13(3):242-65.

2. Pons T, Shipton EA, Williman J, Mulder RT. Potential risk factors for the onset of complex regional pain syndrome type 1: a systematic literature review. Anesthesiol Res Pract. 2015;2015:956539.

3. Beerthuizen A, Stronks DL, Huygen FJ, Passchier J, Klein J, Spijker AV. The association between psychological factors and the development of complex regional pain syndrome type 1 (CRPS1)--a prospective multicenter study. Eur J Pain. 2011;15(9):971-5.

4. Dilek B, Yemez B, Kizil R, Kartal E, Gulbahar S, Sari O, et al. Anxious personality is a risk factor for developing complex regional pain syndrome type I. Rheumatol Int. 2012;32(4):915-20.

5. Lohnberg JA, Altmaier EM. A review of psychosocial factors in complex regional pain syndrome. J Clin Psychol Med Settings. 2013;20(2):247-54.

6. Wager J, Brehmer $\mathrm{H}$, Hirschfeld G, Zernikow B. Psychological distress and stressful life events in pediatric complex regional pain syndrome. Pain Res Manag. 2015;20(4):189-94.

7. Borucki AN, Greco CD. An update on complex regional pain syndromes in children and adolescents. Curr Opin Pediatr. 2015;27(4):448-52.

8. Abu-Arafeh $\mathrm{H}$, Abu-Arafeh I. Complex regional pain syndrome in children: a systematic review of clinical features and movement disorders. Pain Manag. 2017:7(2):133-40.

9. Weissmann R, Uziel Y. Pediatric complex regional pain syndrome: a review. Pediatr Rheumatol. 2016;14(1):29.

10. Cruz N, O'Reilly J, Slomine BS, Salorio CF. Emotional and neuropsychological profiles of children with complex regional pain syndrome type-I in an inpatient rehabilitation setting. Clin J Pain. 2011;27(1):27-34.

11. Lewcun B, Kennedy TM, Tress J, Miller KS, Sherker J, Sherry DD. Predicting suicidal ideation in adolescents with chronic amplified pain: the roles of depression and pain duration. Psychol Serv. 2018;15(3):309-15.

12. Harden RN, Bruehl S, Perez RS, Birklein F, Marinus J, Maihofner C, et al, Validation of proposed diagnostic criteria (the "Budapest criteria") for complex regional pain syndrome. Pain. 2010;150(2):268-74.

13. Harden RN, Bruehl S, Perez RS, Birklein F, Marinus J, Maihofner C, et al. Development of a severity score for CRPS. Pain. 2010;151(3):870-6.

14. Harden RN, Maihofner C, Abousaad E, Vatine J-J, Kirsling A, Perez RS, et al. A prospective, multisite, international validation of the complex regional pain syndrome severity score. Pain. 2017;158(8):1430-6.

15. Hjermstad MJ, Fayers PM, Haugen DF, Caraceni A, Hanks GW, Loge JH, et al. Studies comparing numerical rating scales, verbal rating scales, and visual analogue scales for assessment of pain intensity in adults: a systematic literature review. J Pain Symptom Manag. 2011;41(6):1073-93.

16. Goldsworthy R, Donders J. MMPI-2-RF patterns after traumatic brain injury. Psychol Assess. 2019;31(9):1145-53.

17. Lee J, Nam W. The evaluation of the Korean military personality inventory. Korean Psychol. 2006;6:466-7.

18. Lee J, Nam W, Park J, Lim H, Yoon H, Han J. The relationship between the KMPI and the military personality inventory. Korean Psychol. 2006:6:464-5.

19. Choi K, Im H, Kim J, Choi KH, Jon DI, Hong H, et al. Relationship of early-life stress and resilience to military adjustment in a young adulthood population. Soc Psychiatry Psychiatr Epidemiol. 2013;48(11):1767-76.

20. Oh CH, Park H, Kim E, Hyun DK, Chung J. Influence of Moyamoya disease on psychopathological abnormality in young males in Korea: analysis of multiphasic personal inventory test. Neurol Sci. 2013;34(6):949-53.

21. Kim SH, Hur J, Jang JY, Park HS, Hong CH, Son SJ, et al. Psychological distress in young adult males with atopic dermatitis: a cross-sectional study. Medicine. 2015;94(23):949.

22. Park D, Yook S. A study for screening effect and availability of the military personality test. J Korean Milit Med Assoc. 2004;35:157-69.

23. Choi K, Jung S, Choi K, Moon C, Kim J. Development of new military personality inventory. Seoul: Korea Institute for Defense Analyses; 2009. 2699 Report No Un07.

24. Lee SH, Park YS, Nam TK, Kwon JT. Psychopathological influence of middle Fossa arachnoid cysts in young men: analysis of Korean conscription data. World Neurosurg. 2019;122:e530-9.

25. Bajwa ZH, Wootton $\mathrm{R}$, Warfield CA. Principles and practice of pain medicine. 3rd ed. New York: McGraw-Hill; 2017. 
26. Park HY, Jang YE, Oh S, Lee PB. Psychological characteristics in patients with chronic complex regional pain syndrome: comparisons with patients with major depressive disorder and other types of chronic pain. J Pain Res. 2020; 13:389-98.

27. Monti DA, Herring CL, Schwartzman RJ, Marchese M. Personality assessment of patients with complex regional pain syndrome type I. Clin J Pain. 1998; 14(4):295-302.

28. Rommel O, Willweber-Strumpf A, Wagner P, Surall D, Malin J-P, Zenz M. Psychische Veränderungen bei Patienten mit komplexem regionalem Schmerzsyndrom (CRPS). Schmerz. 2005;19(4):272-84.

29. Fietta P, Manganelli P. Fibromyalgia and psychiatric disorders. Acta Biomed. 2007;78(2):88-95.

30. Su N, Lobbezoo F, van Wijk A, van der Heijden GJ, Visscher CM Associations of pain intensity and pain-related disability with psychological and socio-demographic factors in patients with temporomandibular disorders: a cross-sectional study at a specialised dental clinic. J Oral Rehabil. 2017:44(3):187-96.

31. Margalit D, Ben Har L, Brill S, Vatine JJ. Complex regional pain syndrome, alexithymia, and psychological distress. J Psychosom Res. 2014;77(4):273-7.

32. Bean DJ, Johnson MH, Kydd RR. Relationships between psychological factors, pain, and disability in complex regional pain syndrome and low back pain. Clin J Pain. 2014;30(8):647-53.

33. Logan DE, Williams SE, Carullo VP, Claar RL, Bruehl S, Berde CB. Children and adolescents with complex regional pain syndrome: more psychologically distressed than other children in pain? Pain Res Manag. 2013;18(2):87-93.

34. Mesaroli G, Ruskin D, Campbell F, Kronenberg S, Klein S, Hundert A, et al. Clinical features of pediatric complex regional pain syndrome: a 5-year retrospective chart review. Clin J Pain. 2019;35(12):933-40.

35. McEwen BS, Gianaros PJ. Central role of the brain in stress and adaptation: links to socioeconomic status, health, and disease. Ann N Y Acad Sci. 2010; 1186:190-222

36. Barad MJ, Ueno T, Younger J, Chatterjee N, Mackey S. Complex regional pain syndrome is associated with structural abnormalities in pain-related regions of the human brain. J Pain. 2014;15(2):197-203.

37. Shokouhi M, Clarke C, Morley-Forster P, Moulin DE, Davis KD, St Lawrence K. Structural and functional brain changes at early and late stages of complex regional pain syndrome. J Pain. 2018;19(2):146-57.

38. Tajerian M, Leu D, Zou Y, Sahbaie P, Li W, Khan H, et al. Brain neuroplastic changes accompany anxiety and memory deficits in a model of complex regional pain syndrome. Anesthesiology. 2014;121(4):852-65.

39. Davis KD, Taylor KS, Anastakis DJ. Nerve injury triggers changes in the brain. Neuroscientist. 2011;17(4):407-22.

40. Lee DH, Lee KJ, Cho KIK, Noh EC, Jang JH, Kim YC, et al. Brain alterations and neurocognitive dysfunction in patients with complex regional pain syndrome. J Pain. 2015;16(6):580-6.

41. Baliki MN, Schnitzer TJ, Bauer WR, Apkarian AV. Brain morphological signatures for chronic pain. PLoS One. 2011;6(10):e26010.

42. Becerra L, Sava S, Simons LE, Drosos AM, Sethna N, Berde C, et al. Intrinsic brain networks normalize with treatment in pediatric complex regional pain syndrome. Neuroimage Clin. 2014;6:347-69.

43. Erpelding N, Simons L, Lebel A, Serrano P, Pielech M, Prabhu S, et al. Rapid treatment-induced brain changes in pediatric CRPS. Brain Struct Funct. 2016;221(2):1095-111.

44. Linnman C, Becerra L, Lebel A, Berde C, Grant PE, Borsook D. Transient and persistent pain induced connectivity alterations in pediatric complex regional pain syndrome. PLoS One. 2013;8(3):e57205.

45. Yang S, Chang MC. Chronic pain: structural and functional changes in brain structures and associated negative affective states. Int J Mol Sci. 2019;20(13): 3130.

46. Stanton-Hicks M. Plasticity of complex regional pain syndrome (CRPS) in children. Pain Med. 2010;11(8):1216-23.

\section{Ready to submit your research? Choose BMC and benefit from:}

- fast, convenient online submission

- thorough peer review by experienced researchers in your field

- rapid publication on acceptance

- support for research data, including large and complex data types

- gold Open Access which fosters wider collaboration and increased citations

- maximum visibility for your research: over $100 \mathrm{M}$ website views per year

At BMC, research is always in progress.

Learn more biomedcentral.com/submissions 